\title{
Nanostructured mesoporous carbon as electrodes for supercapacitors
}

\begin{abstract}
Symmetrical carbon/carbon double layer capacitors (EDLCs) were fabricated employing nanostructured mesoporous nongraphitized carbon black (NMCB) powders and their EDLC behavior was studied using electrochemical techniques viz., cyclic voltammetry, a.c.impedance, and constant current cycling. Rectangular shape cyclic characteristics were observed indicating the double layer behavior of the NMCB carbon electrodes. The mechanism of double layer formation and frequency dependent capacitance were deduced from the ac-impedance analysis. Specific capacitance, power density and energy density were derived from constant current charge/discharge measurements. NMCB powders demonstrated a specific capacitance of about $\sim 39 \mathrm{~F}$ gī 1 and the power density of $782 \mathrm{~W} \mathrm{kgī} 1$ at a current density of $32 \mathrm{~mA} \mathrm{cmī} \mathrm{2.} \mathrm{Nevertheless,} \mathrm{at} \mathrm{a} \mathrm{low} \mathrm{current} \mathrm{density} \mathrm{(} 3 \mathrm{~mA} \mathrm{cmi} \mathrm{2),} \mathrm{the} \mathrm{specific}$ capacitance of $\sim 44 \mathrm{~F}$ gī 1 was achieved, which corroborates with the values obtained by means of ac-impedance (40 F gī 1) and cyclic voltammetry (41.5 F gī 1). The test cells demonstrated the stable cycle performance over several hundreds of cycles.
\end{abstract}

Keyword: Mesoporous carbon; Carbon electrodes; Supercapacitors; Nanostructure; Electrochemical properties 